\title{
(息)
}

Citation:

Morgan, J (2016) Paris COP 21: Power that Speaks the Truth? Globalizations, 13 (6). pp. 943-951. ISSN 1474-7731 DOI: https://doi.org/10.1080/14747731.2016.1163863

Link to Leeds Beckett Repository record:

https://eprints.leedsbeckett.ac.uk/id/eprint/2668/

Document Version:

Article (Accepted Version)

The aim of the Leeds Beckett Repository is to provide open access to our research, as required by funder policies and permitted by publishers and copyright law.

The Leeds Beckett repository holds a wide range of publications, each of which has been checked for copyright and the relevant embargo period has been applied by the Research Services team.

We operate on a standard take-down policy. If you are the author or publisher of an output and you would like it removed from the repository, please contact us and we will investigate on a case-by-case basis.

Each thesis in the repository has been cleared where necessary by the author for third party copyright. If you would like a thesis to be removed from the repository or believe there is an issue with copyright, please contact us on openaccess@leedsbeckett.ac.uk and we will investigate on a case-by-case basis. 


\section{Paris COP 21: Power that Speaks the Truth?}

JAMIE MORGAN

Leeds Beckett University, Leeds, UK

ABSRACT In the following paper I set out some of the key aspects of the Paris COP 21 Climate Change Agreement. The Paris Agreement was initially reported as a major success. However, this was in so far as many thought any kind of agreement at all was unlikely, and because the Agreement includes Article 2: an aspiration to maintain average global temperature increases to significantly less than $2^{\circ} \mathrm{C}$. I then ask the question: if the Paris Agreement is a success of sorts, has anything fundamental changed in order to translate the conditional success of achieving an agreement into an actual success that will realise the goals of the Agreement? I address this in terms of early assessment of trends and the Nationally Determined Contributions (NDCS), how responsibility is positioned in the Agreement, and the political economy context, which has called forth the need for an agreement.

Keywords: the Paris Agreement, Climate Change, political economy

Jamie Morgan works at Leeds Beckett University, UK. He edits Real World Economics Review with Edward Fullbrook. He has published widely in economics, political economy, sociology, philosophy and area studies. He is currently working on problems of taxation of multinational corporations, as well as institutional iteration effects of financial stability.

\section{Introduction}

The Paris COP 21 Climate Change Agreement arrived with great public fanfare in December 2015 (UNFCCC, 2015). It then faded from view as the media and public turned and returned to other matters (terror alerts, Syria, migration, the Fed interest rate decision, shopping and Christmas). That attention moved on so quickly is instructive. On the one hand, the Agreement was presented as a diplomatic triumph, and this can readily convey the impression that the issues addressed through the Agreement are now resolved, and everything is on track to deal with the fundamental problem of greenhouse gas emissions (GHGs) and human induced global warming. According to a White House press release:

This new global framework lays the foundation for countries to work together to put the world on a path to keeping global temperature rise well below $2^{\circ} \mathrm{C}$ and sets an ambitious vision to go even farther than that. This agreement sends a strong signal to the private sector that the global economy is moving towards clean energy, and that through innovation and ingenuity, we can achieve our climate objectives while creating new jobs, raising standards of living and lifting millions out of poverty. The Paris agreement is also the culmination of a broader effort by nations, businesses, cities, and citizens to reorient the global economy to a path of lowcarbon growth - progress that will accelerate as a result of the agreement's provisions on mitigation ambition, transparency, and climate finance. (Office of the Press Secretary, 2015)

According to UK Prime Minister David Cameron:

Today is an important day. The talks at the COP21 conference in Paris have culminated in a global deal, with every country in the world now signed up to play its part in halting climate change. In other words, this generation has taken vital steps to ensure that our children and 
grandchildren will see that we did our duty in securing the future of our planet. (Cameron, 2015)

On the other hand, the actual basis of the diplomatic triumph was simply to achieve any kind of agreement at all, given that the original Kyoto Protocol period had run its course, and the Copenhagen negotiations of 2009 had ended in acrimony. As it turned out, the Paris Agreement included (Article 2) a surprise reference to an aspiration to keep global average temperature rises 'well below' $2^{\circ} \mathrm{C}$ and make 'efforts' towards $1.5^{\circ} \mathrm{C}$.' However, Paris COP 21 is an agreement that things need to be done. It is not an agreement of what will be done, by whom, and to what degree, rooted in the actual science and forecasts from the various authoritative sources (notably the IPCC, fifth assessment report, AR5, 2015). In what follows I set out some of the arising issues, focusing in particular on the question: if the Paris Agreement is a success of sorts, has anything fundamental changed in order to translate the conditional success of achieving an agreement into an actual success that will realise the goals of the Agreement?

\section{What form of agreement has COP 21 created?}

The statement that the Paris Agreement is not an agreement of what will be done, by whom, and to what degree is one that requires further specification. More accurately the Paris Agreement does not categorically state: here is the current rate of global emissions, here is the rate at which each country is generating emissions, here is a distribution of legally binding definite sums of emissions for each country which will ensure that emissions do not exceed a threshold, and which will guarantee that emissions actually reduce. Instead, it is an agreement that each country, and perhaps regional economic institution (the Parties of the Agreement), will submit a Nationally Determined Contribution (NDC), which sets out its own target for a slowdown in emissions growth and then, according to its own timeline, actual reductions to achieve a balance by, at the latest, 'the second half of the century' (Article 4). This includes through as yet untried, untested, or undeveloped carbon neutralising strategies and technologies, and also allowing for offsetting mechanisms or transfers, rather than actual reductions within given countries (Article 6).

What the Parties have signed up to is an Agreement to 'recognize' that the problem of climate change is 'urgent', and that each will use the Article 2 aspiration as a reference point, in regard of which each will be 'ambitious' and address the problem of emissions reduction 'progressively'. The significant sense of achievement this induced in some quarters - including from Nicholas Stern - was predicated on real progress being subsequently made (the potential created by having an agreement and from Article 2). The hope then becomes that the existence of the NDCs (collated in a public register at the UN in New York) will create momentum and pressure for Parties to produce genuinely ambitious targets and to then exceed them. This sense is interwoven into the language of the text, which makes repeated reference to the kind of language stated above (urgent etc), and Article 12, which specifically states the need to enhance climate change education and public awareness, and Article 14, which introduces a collective stocktaking exercise, beginning in 2023, to be undertaken every 5 years thereafter. The purpose of the stocktake is to assess collective progress towards Article 2. The important point here is that it is implicit in the Agreement that it will meet its goals through aggregated individual efforts (a bottom up approach), subject to using others as a reference point, and based on the assumption that individual Parties will recognize responsibilities and real interests, and respond to public awareness.

Clearly then, it is extremely important that climate change remains a central and visible issue within the politics of all societies at all times. It must remain an immediate collective issue, where the long term dominates other short-term considerations. The justifiably febrile nature of public attention 
and the many shifts and demands on policy, local, regional and global invite scepticism in this regard. Moreover, precisely because attention and concerns can shift and be diverted, one might argue that an effective agreement ought to be more specific in order to constrain and dictate to the Parties, based on what needs to be done. If urgent and ambitious were genuinely meaningful, in the ordinary language sense a member of the public might be tempted to infer (from the Agreement's liberal use of the terms), one would expect the actual construction of the Agreement to be a disciplinary force that directly addresses problems of short termism and distraction, rather than assumes that aggregated effects on the Parties will overcome problems of short termism and distraction (via public awareness etc). Of course, a sceptic would not assume all Parties were looking for their citizens to keep them 'honest' and focused. The Agreement is no more or less than the product of negotiation between many asymmetrically powerful actors with varying current concerns and interests over and above climate change. Optimists might point out that COP 21 is progress of sorts because, unlike Kyoto (in its early form), all countries are expected to be signatories (strictly speaking the Agreement remains inactive until 55 members constituting at least $55 \%$ of measured emissions have ratified the Agreement and formal signing, subsequent to Parties returning to their own polities, does not open until April 2016, Articles 20 \& 21). This seems to imply that all countries are finally acknowledging responsibility. However, it is a stretch to infer responsibility is genuinely acknowledged simply because Parties are all willing to sign a potentially weak and essentially voluntary Agreement. A willingness to sign the Agreement might signal the opposite - in so far as there is nothing in the Agreement to compel signatories to take responsibility, and its actual form may allow Parties to continue to shift responsibility (in terms of who acts first and to what degree) around. This possibility leads to a different issue of context. If the Agreement is a success of sorts, has anything fundamental changed in order to translate the conditional success of achieving an agreement into an actual success that will realise the goals of the Agreement? There are, unfortunately, further grounds for scepticism here."

\section{Early assessment of trends and the NDCs}

In October 2015 the UNFCCC released a preliminary assessment of communicated intended NDCs (INDCs). The 119 INDCs submitted covered 147 Parties (since it also included the European Union) responsible for an estimated $86 \%$ of total emissions in 2010 . The INDCs themselves covered only an estimated $80 \%$ of emissions sources, since not all INDCs included all possible GHGs or all sectors of the economy/society that might be responsible for emissions. However, based on the submitted INDCs, the UNFCCC estimated that emissions would exceed the IPCC target for its 'least cost' (meaning

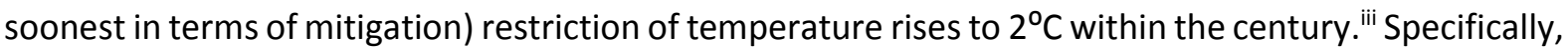
the period covered by the initial INDCs would exceed $\mathrm{CO}_{2}$ equivalent emissions by 4.7-13 gigatonnes in 2025, and by 11.1 to 21.7 gigatonnes in 2030 (UNFCCC, 2015a: pp. 10-12). This implies that, thereafter, greater efforts would need to be made to get back on track. Subsequent research reported by the Tyndall Centre highlights that without the INDCs (increased to 185 Parties in the Tyndall assessment) then global average temperature rises could reach $5.2^{\circ} \mathrm{C}$ by 2100 (Tyndall Centre, 2015). However, as various analysts have noted, the current INDCs imply a likely temperature rise of $2.7^{\circ} \mathrm{C}$, and as Ajay Gambir, lead scientist at the Grantham Institute, Imperial College London notes, though it is technically feasible that the world could still achieve the $2^{\circ} \mathrm{C}$ threshold, it is becoming increasingly unlikely as delays occur and emissions accumulate in the atmosphere (Ibid). The UNFCCC assessment clearly states that all outcomes will be conditional on significant changes in 'socioeconomic drivers', 'technology', and greater action to reduce emissions by Parties (UNFCCC, 2015a). Parties are 'urged' under the terms of the Paris Agreement to submit a new NDC every 5 years beginning in 2020 (though INDCs are currently time-framed up to either 2025 or 2030), and to do so with sufficient leeway to allow a new synthesis progress report on each occasion (UNFCCC, 2015: p. 4). However, the initial 
assessment makes it clear that the likely NDCs are already deferring action into the future, and Parties are assuming that more significant changes will occur then (social redesign, social change, technology) rather than now. One might also note the assessment highlights that many of the INDCs are incomplete, and not necessarily commensurable or comparable, since they lack a common method, focus or system - the text is replete with use of terms such as 'many' and 'some' when referring to what is actually in the INDCs of Parties. This is despite that the Paris Agreement repeatedly calls for 'clarity and transparency' (e.g. Article 4), states that information provided will undergo 'technical expert review' (Article 13), and that this is essential to any effective stocktaking (stated in Article 14). iv A sceptic might wonder whether Parties are already beginning to position their NDCs to place their actual emissions levels in the best possible way (extending to the possibility of gaming the statistics).

\section{Taking responsibility?}

One cannot ignore that the Paris Agreement has context in terms of attempts to distribute responsibility (rather than actually dictate the distribution of real emissions targets). When referring to the development of NDCs, and then possible progress or progressive updating of them, the Paris Agreement refers to the need for 'flexibility' and repeatedly uses the phrase: 'common but differentiated responsibilities and respective capabilities, in the light of different national circumstances' (e.g. UNFCCC, 2015: p. 20). Consider what the text of the Agreement does not contain or refer to. The term 'contribution' is used rather than commitment. There is no mention of causation for emissions. GHGs are referred to briefly in the initial communication and in Articles 4 \& 6 (UNFCCC, 2015: pp. 3, 21 \& 26), but there is no mention of specific types and sources of emissions (oil, coal and gas), or of key sectors of economies and societies creating them (aviation, transport in general, energy production, industrial agriculture). There is no mention of which countries are the primary sources of emissions, nor of the per capita rates of emissions and the reasons those emissions are created (domestic or goods for export - creating issues of real carbon footprints). There is no mention of the role of corporations or of the link between wealth, consumption, waste and emissions. There is no mention of the problem of growth, merely of the opportunities for growth (Article 10). As such, there is no mention of the issue of models of economy that are developed, emulated and/or disseminated, and of changes in income and population that can and do offset any attempts to decrease absolute emissions (as opposed to measures such as energy intensity GDP). There is no mention of potential conflicts between different aspects of 'sustainable development', merely of the need to be sensitive to all the arising aspects of it (repeatedly stated as a sub-clause in various articles).

Clearly, Parties are all aware of what is not in the text, and so omission is not ignorance. But if one considers the text as a product of negotiation regarding language, then the Paris Agreement begins to appear, rather than merely neutral, purposefully anodyne, if not to say deliberately soporific, despite the claim to urgency. There is a refusal to use a language of actual responsibilities. Consider then how 'common but differentiated responsibilities and respective capabilities, in the light of different national circumstances' is being used. 'Responsibilities', 'capabilities', and 'circumstances' have no intrinsic meaning. They are given substance in terms of what Parties are prepared to sacrifice, change or commit to in order to avoid collective adverse consequences. By evading definitive context for the terms, the Agreement evades stating what the real baseline commitments or interests that modify the terms really are. Ultimately, one can only judge what those are based on the context in which all Parties continue to act as the Agreement unfolds. However, if one considers the omissions, then the underlying commitments whose power has been expressed through omission, do not invite confidence.

\section{Problems of political economy}


What is omitted in the Paris Agreement is an explanatory account of the political economy within which climate change has been created, and which has so far helped to shape how it has been addressed. This is important because it may well affect the way 'solutions' continue to develop. The dynamics of this are global in many ways. Problems of resource use and depletion, and ecologicalenvironmental harm and degradation are not new. They have been recognized now for at least forty years (for example, Schumacher, 1973/1993; Meadows et al, 1972; Latouche, 2010; Daly, 2015). They have been a mainstream issue, typically captured under the awkward and perhaps oxymoronic phrase sustainable development, since at least the Brundtland Commission report (WCED, 1987, see also Seghezzo, 2009). As the data collated in the periodic UNEP Global Environmental Outlook reports make clear, recognition has not resulted in countries effectively addressing basic trends (e.g. UNEP, 2012). The world has continued to do unsustainable things whilst sustainable development policies have multiplied. Problems have accumulated and intensified. ${ }^{v}$

Part of the reason problems have been allowed to accumulate has been a basic economism. A fundamental and problematic conflation and inversion has developed. The acknowledgement that it is economic activity that causes ecological-environmental problems has been conflated with the understanding that it is through economic processes that such problems will be resolved. This in turn has involved an inversion where ecological-environmental problems are referenced to the economy, and the basic framing concern becomes, what changes are compatible with least harm to the economy? This has become so ingrained in contemporary thinking that we tend to forget how strange this logic actually is when thinking about the environment, and in terms of the way economics is positioned as theory and how economic activity is pursued. It treats ecological-environmental problems as if they were just one more problem, rather than a basic or fundamental conditioning context. It has promoted a situation in which environmental (and then the more critical ecological) economics has become a sub-discipline of economics, as though problems can be delegated to some small proportion of the field of economics, rather than its insights become basic to the very way an economy is defined and understood (see Spash, 2013; Nadeau, 2015; Morgan, 2015). This in turn has affected the way problems are reconciled within theory and policy, and this too has a political economy context.

Government intervention and institution building over the period in which the discourse of sustainable development has emerged has tended to adopt market conforming and market creating solutions to ecological-environmental problems. Rather than intervene early to prohibit activity, directly compel alternatives, and provide the basic investment and infrastructure for those alternatives (including through basic social redesign), developing nations have typically deferred the problem whilst developed states have mainly adopted policies to internalise some externalities through taxation, as well as create synthetic markets to make emissions tradable (these, for example, were basic to the Kyoto Protocols). In terms of the latter policies (externalities and then synthetic markets), both assume that one can fix markets, such that solutions emerge as unintended consequences of economic activity caused by (corrected or created) price signals that serve to voluntarily and gradually change consumer behaviour, affect resource use, and promote investment for alternative technologies (at the same time as states also try to educate the citizen and persuade the corporation). However, the basic logic remains one where it is substitutions brought about by rising costs, predicated on growing resource exhaustion and actual economically quantifiable environmental harm that induces change. But think about what that really means - in environmental terms it means ducking after one has been punched. In environmental terms it means assuming a particular market can recognize a trans-market ecological-environmental threshold (qua consequences) beyond which it will be dangerous for economic activity to continue (even though the effects may be created in some period significantly before they manifest due to cumulative effects 
and sudden feedback effects in poorly understood non-linear dynamic systems). ${ }^{\text {vi }}$ In terms of social logic it means waiting until an economy tells one it is now 'cost effective' (or reasonable based on achieved economic development) before one actually addresses the problems science identified years before as existent, and accumulating. It means also assuming that it is economic development as growth and through growth, and mainly technology as some induced response that will solve the problems created. This is the same for mitigation arguments as it is for adaptation arguments, if you consider the issues from any other context than a dominant economic frame of reference. It may well also be the case for the emerging focus on green growth and Keynesian approaches to sustainability (Holt et al, 2009).

Of course, one might respond that material improvements are important (particularly in the context of some countries and the issue of poverty etc), that growth can be desirable and has many potential welfare benefits, and that technology is one important way in which societies progress and create new potentials and solve old problems. However, this is not quite the point. The issue at stake is collective based on the type of growth pursued within the type of economies created. Global agreements such as Paris are called forth because of the effects of globalisation. Older capitalist economies have growth models predicated on continually renewed and diversifying consumption. This in turn is underpinned by the spread of industrialisation to other economies to which production is outsourced (to perpetuate growing consumption through underlying deflationary effects). The spread brings with it urbanisation, material development, and new sources of domestic pollution (whilst tending to expand the real carbon footprint in de-industrialised core economies that may in other ways appear to be decarbonising). It also creates newly affluent consuming populations. The issue is not whether we find this desirable, but rather whether the planet can tolerate this activity from a species. Whether it can, in part, depends on whether the ways we have developed to address ecological-environmental problems are proving viable, and if not whether any alternatives are on the horizon.

\section{Carbon emission trends and technology}

Clearly, there are many initiatives being undertaken around the world to address particular problems in particular places (carbon neutral homes and cities, uses of the Internet of things, electric cars etc), but what matters most are effects in the aggregate and the dominant framing of policy. It is worth noting that so far carbon trading has done little in terms of reducing actual emissions anywhere. Even its strongest advocates recognize that prices in carbon markets have never been of a level likely to create a significant cost of production, though they have been part of significant profits for the banks who operate the market (see Newell et al, 2013; Koch, 2014). One might also note that despite the existence of attempts to internalise some emissions-related externalities, and also to create carbon trading markets, IMF research indicates that there are simultaneously perverse multi-trillion Dollar subsidies that sustain a dependence on oil around the world (Coady et al, 2015; also, Di Muzio, 2015). Moreover, as Helm (2012) makes clear, fracking has changed the context for carbon dependence. A decade ago one might have assumed market processes would see the world gradually shift from carbons, as oil and gas prices rose. This is no longer the case and is unlikely to be so within a relevant timeframe for climate change. BP's recent Technology Outlook report indicates proven oil reserves are increasing rather than decreasing (up from 2.9 to 4.8 trillion barrels; 2015: p. 9). As such, there is more of a pressure to leave more of this resource in the ground, even as its price remains newly low. Furthermore, the recognition that one should not use a resource is not quickly translating into actually refusing to do so. Both China and India remain heavily dependent on coal power stations for energy production and both are planning to build more. For example, China has plans to build 803 plants and India a further 193 (Webster, 2015; see also Smith, 2015). 
A reliance on technology to eventually address the problem of emissions thus faces significant challenges. In the last decade, Jackson (2009) calculated that technology would have to deliver a decrease in emissions twenty-one times faster than the current trend in energy-intensity GDP if the IPCC $2^{\circ} \mathrm{C}$ target was to be met. The only change since then has been an actual increase in total annual global emissions (though this stalled in 2015). A technology solution seems to require some kind of major transformative Kondratieff wave focussed on the emissions problem. The Paris Agreement seems to be doing little to change the way we think about solutions to climate change. Article 6 states new technologies will play a significant role in achieving Article 2 , and as we have also noted the initial INDCs imply that major change is deferred and will partly be dependent on technological change.

However, there is a significant difference between actually making changes now (including through new technology) and allowing trends to continue such that there will be a future need for miraculous technological effects in the future. The former is reasonable and the latter is reckless. The difference indicates something about real commitments and 'urgency' and one might make a similar comment regarding general issues like taxing externalities. An effective carbon tax (in the context of the elimination of simultaneous subsidies and as a substitute for a corporation-friendly carbon trading system) is not necessarily superfluous or pointless. In some respects such a carbon tax could be one important way to fund adaptations already required in some countries, and to support social redesign and alternative development strategies in others. Concomitantly, this might provide a real basis for some of the funding discussed in Paris and provisionally incorporated into the Agreement (though without formal specific commitments from individual states) as a financial mechanism. However, the prospects for this so far seem slim, precisely because of disputes over who will take responsibility and in what ways.

\section{Conclusion}

If we return to the question, has anything fundamental changed in order to translate the conditional success of achieving an agreement into an actual success that will realise the goals of the Paris Agreement, it seems reasonable so far to tend to the negative. One might go so far as to suggest, in context, the Paris Agreement currently represents a collective violation of the precautionary principle. That is, Principle 15 of the 1992 Rio Earth Summit declaration, which states that lack of absolute certainty is not sufficient reason to defer prudential activity. This is despite that the preamble to the Paris Agreement states the 'importance of ensuring the integrity of all ecosystems' (UNFCCC, 2015: p. 20). In concluding, it is important to recall a basic insight of ecological economics, the planet does not recognize, register or respond to good intentions or partial efforts. One either does what is necessary or one does not. From this perspective the Paris Agreement seems to call forth a most basic question: are we a species sufficiently intelligent to recognize our own imminent demise, but too stupid to prevent it?

\section{References}

BP (2015) Technology Outlook London: BP Plc http://www.bp.com/content/dam/bp/pdf/technology/bp-technology-outlook.pdf

Cameron, D. (2015) 'Facebook post' December $12^{\text {th }}$, https://www.facebook.com/DavidCameronOfficial/posts/1093255924032058

Coady, D. Parry, I. Sears, L. and Shang, B (2015) 'How large are global energy subsidies?' Fiscal Affairs Dept, IMF Working Paper 105

Daly, H. (2015) Essays Against Growthism London: WEA Books 
Di Muzio, T. (2015) Carbon Capitalism: Power, Social Reproduction and World Order London: Rowman \& Littlefield

Helm, D. (2012) 'Peak oil and energy policy - a critique', Oxford Review of Economic Policy 27(1): 6891

Holt, R. Pressman, S. and Spash, C. editors (2009) Post-Keynesian and Ecological Economics: Confronting Environmental Issues Cheltenham: Edward Elgar

IPCC (2015) Climate Change 2014: Synthesis Report Geneva: IPCC

Jackson, T. (2009) Prosperity Without Growth London: Earthscan

Koch, M (2014) 'Climate change, carbon trading and societal self-defense', Real World Economics Review 67: 52-66

Latouche, S (2010) Farewell to Growth Cambridge: Polity

Meadows, D. Meadows, D. Randers, J. and Behrens, W. (1972) The Limits to Growth New York: American Library

Morgan, J. (2015) 'Is economics responding to critique? What do the UK 2015 QAA Benchmarks indicate?' Review of Political Economy 27(4): 518-538

Nadeau R. (2015) The unfinished journey of ecological economics', Ecological Economics 109: 101108

Newell, R. Pizer, W. and Raimi, D. (2013) 'Carbon Markets 15 years after Kyoto: Lessons Learned, New Challenges', Journal of Economic Perspectives 27(1): 123-146

Office of the Press Secretary (2015) 'US Leadership and the Historic Paris Agreement to Combat Climate Change', Washington DC: The White House, December $12^{\text {th }}$ https://www.whitehouse.gov/the-press-office/2015/12/12/us-leadership-and-historic-parisagreement-combat-climate-change

Schumacher, E. F. (1973/1993) Small is Beautiful: A Study of Economics as if People Mattered London: Vintage

Seghezzo, L. (2009) 'Five dimensions of sustainability', Environmental Politics 18(4): 539-556

Smith, R (2015) 'China's Communist-Capitalist ecological apocalypse', Real World Economics Review 71: $19-63$

Spash, C. (2013) 'The shallow or the deep ecological economics movement?' Ecological Economics 93: 351-362

Stern, N. (2013) 'The structure of economic modelling of the potential impacts of climate change: grafting gross underestimation of risk onto already narrow science models', Journal of Economic Literature 51(3): 838-859

Tyndall Centre (2015) 'Press Release: Climate change pledges could avoid effects of global warming', Tyndall Centre for Climate Change Research, University of East Anglia, December $14^{\text {th }}$ http://www.tyndall.ac.uk/communication/news-archive/2015/climate-change-pledgescould-avoid-effects-global-warming

UNFCCC (2015) 'Adoption of the Paris Agreement and Annex: Paris Agreement', Paris/New York: United Nations Framework Convention on Climate Change, Draft, December $12^{\text {th }}$

UNFCCC (2015a) 'Synthesis Report on the aggregate effect of the intended nationally determined contributions', New York: United Nations Framework Convention on Climate Change, October $30^{\text {th }}$

UNEP (2012) Global Environmental Outlook Report 5: Environment for the Future We Want New York: United Nations Environment Programme

WCED (1987) Report of the World Commission on Environment and Development: Our Common Future New York: United Nations http://www.un-documents.net/wced-ocf.htm

Webster, B. (2015) '2,500 new coal plants will thwart any Paris pledges', The Times December $2^{\text {nd }}$

\footnotetext{
i The temperature reference point is pre-industrial levels in all cases where ${ }^{\circ} \mathrm{C}$ is used.

ii A useful point of departure for sources of critique regarding COP21 can be found at: http://www.flassbeckeconomics.de/the-paris-climate-change-agreement-is-an-epic-failure/
} 
iii This is also noted 'with concern' in the communication for the adoption of the Agreement, Part II (UNFCCC, 2015: p. 3)

iv The communication for adoption notes the need 'to assist in the improvement of transparency over time', as if somehow this was intrinsically difficult rather than a lack of consistency, coherency and willingness to agree had created the difficulty; it also states Parties may include 'as appropriate' a whole range of different varieties of information (UNFCCC, 2015: pp. 4 \& 12)

${ }^{\vee}$ For example, according to the UNEP the regenerative capacity of the Earth had already been exceeded in 2007. According to the International Union for the Conservation of Nature (IUCN), which produces the species 'Red List', current extinction rates are 100 times faster than the fossil record indicates is normal.

vi This is despite a recent extraordinary admission from the leading economist in the field, in a 2013 essay Nicholas Stern acknowledges that all mainstream economic models of these processes distort and underestimate climate effects. 